* Mestranda em Direitos Coletivos e Cidadania pela Universidade de Ribeirão Preto - UNAERP. Bolsista PROSUP/CAPES. Especialista em Direito Processual Civil pela Universidade de Ribeirão Preto - USP. Graduada em Direito pela Universidade de Ribeirão Preto - UNAERP.

E-mail: oni126@msn.com

**Doutor e mestre em Direito pela PUC/SP. Professor de Direito do Mestrado e Doutorado da Universidade de Ribeirão Preto UNAERP. Professor convidado do curso presencial de pós-graduação "lato sensu" em Direito Processual Civil da Faculdade de Direito da USP - Ribeirão Preto (FDRP/ USP). MBA Executivo pela FGV (Fundação Getúlio Vargas). Membro efetivo e diretor de Relações Institucionais do IASP. Membro efetivo do IAB (Instituto dos Advogados Brasileiros). Parecerista e consultor da revista do Conselho da Justiça Federal. Advogado.

E-mail: zgneto@uol.com.br.

\section{A (IN)DisponibiLIDADE Dos Direitos Transindividuais Em Ação Civil Pública: Análise do Caso Dos Planos Econômicos}

\author{
The (In)Availability Of Transindividual Rights In \\ Class Actions: Analysis Of The Case Of Economic \\ Plans
}

\section{Oniye Nashara Siqueira* Zaiden Geraige Neto **}

Como citar: SIQUEIRA, Oniye Nashara; NETO, Zaiden Geraige. The (in)availability of transindividual rights in class actions: analysis of the case of economic plans. Scientia Iuris, Londrina, v. 25, n. 1, p. 87-108, mar. 2021. DOI: 10.5433/2178-8189.2021v25n1p87. ISSN: 2178-8189.

Resumo: $\mathrm{O}$ estudo analisa os limites da renúncia aos direitos transindividuais no âmbito da Ação Civil Pública (ACP), trazendo discussões acerca da natureza (in)disponível destas pretensões. Para tanto, iniciamos apontando o perpassar histórico da defesa coletiva para transcorrer sobre a existência de impedimentos à disposição dos direitos transindividuais a partir do exame do caso dos expurgos inflacionários decorrentes dos planos econômicos no Brasil, mais precisamente a validade e extensão do Acordo Coletivo realizado no bojo das ACPs que versavam sobre a controvérsia. Concluímos pela existência de limitações expressas à disposição de direitos transindividuais pelos legitimados das ACP. Para tanto, aplicamos o método de abordagem dedutivo, em conjunto com a técnica de pesquisa bibliográfica.

Palavras-chave: Renúncia. Expurgos inflacionários. Direitos coletivos

Abstract: This study analyzes the limits of transindividual rights waivers in the context of Brazilian Public Civil Actions (ACP) and discussions the (un)available nature of these claims. To this end, this paper first explores the historical background of collective defenses and then examines the impediments of transindividual rights from the perspective of the many inflationary purges that were direct results of economic plans in Brazil. Moreover, this paper investigates the validity and extension of Collective Agreements made in the context of the ACPs dealing directly with this problem. Finally, this study concludes that there are express limitations to the disposition of transindividual rights by 
the parties of ACPs. This paper utilized the deductive approach, in conjunction with literature review.

Keywords: Renounce. Inflationary purges. Collective rights. 


\section{INTRODUÇÃO}

Diante da tendência de transcendência das discussões individuais para o âmbito coletivo, e considerando a necessidade de tutelar os interesses de grupos vulneráveis e de bens públicos, como o meio ambiente e o patrimônio estatal, o legislador importou para o ordenamento nacional o instituto da Ação Civil Pública (ACP), regulamentada pela Lei no 7.347, editada em 1985.

Referida disposição normativa, que em muito se baseou na class action estadunidense, representou verdadeiro marco na evolução da proteção de direitos e interesses transindividuais no Brasil, consolidando o espírito garantista do legislador pátrio e materializando-a como principal instrumento de acesso à justiça para a defesa dos direitos coletivos lato sensu.

Inúmeras temáticas são tratadas pela coletivização de litígios, destacando-se pela maior incidência nos Tribunais as postulações sobre benefícios previdenciários, meio ambiente, servidores públicos, judicialização da saúde e, no âmbito consumerista, o caso dos expurgos inflacionários, que culminou no ajuizamento de diversas ações civis públicas e incontáveis demandas individuais sobre o tema (SBDP, 2017).

A controvérsia acerca dos expurgos decorre, basicamente, da aplicação à menor dos índices de correção monetária pelas entidades bancárias às contas dos poupadores e que são resultantes das taxas inflacionárias dos planos econômicos, por sua vez, criados pelos governos de 1986 (Cruzado), 1987 (Bresser), 1989 (Verão), 1990 e 1991 (Collor I e II). O entrave reside na cobrança das diferenças entre o percentual aplicado pelos bancos e o quanto invocado pelos correntistas.

Em meados de 2018, e visando colocar fim à discussão que já se estendia no Judiciário há duas décadas ${ }^{1}$, foi anunciado ao grande público, pela mídia nacional ${ }^{2}$, a efetivação do "Instrumento de Acordo Coletivo" entabulado entre as associações de proteção dos consumidores e as entidades bancárias.

A problemática, no entanto, emana da extensão dos efeitos do negócio jurídico e dos termos avençados pelas partes, especialmente as renúncias. Ao estabelecer que todas as demandas coletivas que versam sobre o tema serão extintas por transação e limitar os consumidores beneficiados pela avença àqueles que ajuizaram as próprias demandas individuais, ou habilitaramse nas coletivas por meio de execução/cumprimento de sentença, verifica-se a existência de uma espécie de renúncia irrestrita à direitos transindividuais.

Tais fatores embasam questionamentos acerca da legalidade da transação, da extensão da renúncia e da possibilidade de invalidação de seu conteúdo que se ancoram no estudo da (in)disponibilidade dos direitos coletivos na ACP e nos limites da disposição/renúncia pelos legitimados.

1 Não obstante a imensa quantidade de processos que versam sobre o assunto e que estão submetidos ao Poder Judiciário (estimados em mais de 1 milhão), grande parte mantinha-se suspensa por determinação dos Tribunais Superiores - a quem competia o julgamento dos recursos repetitivos, porém sem perspectiva para tanto.

2 Após a homologação do instrumento de Acordo Coletivo pelo Supremo Tribunal Federal, os jornais brasileiros, tanto televisivos quanto os impressos ou online (Globo, Record, Bandeirantes, Conjur, Jota, et coetera) veicularam aos consumidores a possibilidade de aderência aos termos da composição. 
Deste modo iniciamos a discussão mediante o esclarecimento das peculiaridades da transindividualidade dos direitos coletivos, traçando um breve escorço histórico sobre a trajetória do reconhecimento dos interesses das massas, desaguando na Lei da Ação Civil Pública brasileira.

Após, abordamos o caso dos planos econômicos e as consequências do Acordo Coletivo entabulado, realizando a análise da eficácia, eficiência e validade do negócio jurídico à luz da interpretação de princípios basilares do direito pátrio, fulcrando a crítica na doutrina sobre o tema e fundamentando nosso entendimento no ordenamento vigente. Para tanto, aplicamos o método de abordagem dedutivo, em conjunto com a pesquisa bibliográfica.

\section{RELATO HISTÓRICO DOS DIREITOS COLETIVOS}

O perpassar histórico de efetivação dos direitos transindividuais contempla em seu bojo importantes marcos que delinearam o cenário atual e nos fazem compreender a importância e a indispensabilidade de proteção desta categoria de "novos" direitos.

A concreção dos interesses coletivos está intimamente relacionada ao desenvolvimento histórico dos direitos humanos fundamentais, sendo a história destes composta por lutas de diferentes aspirações e ideais, a partir dos quais foram estabelecidos limites e critérios para o exercício de autoridade e poderes, e tem mudado de acordo com o desenvolvimento da humanidade (GUERRERO, 2018).

Assim, acontecimentos como a Segunda Guerra Mundial (que culminou na Declaração Universal dos Direito Humanos), as Ditaduras Militares no Brasil (das quais derivou a Constituição de 1988) e, ainda, a Revolução Francesa foram determinantes à positivação dos direitos transinviduais. Decorre desta última, inclusive, a teoria de Karel Vasak (1982) acerca das gerações de desenvolvimento dos direitos humanos de acordo com a afirmação nas sociedades, e que coincide com os ideais de "liberté, égalité, fraternité".

O autor equipara o estudo e desenvolvimento dos direitos transindividuais aos ideais do movimento francês ao propor que os direitos de liberdade representam a $1^{\text {a }}$ geração que, por sua vez, é pautada no impedimento estatal de interferência no indíviduo, implicando em prestações negativas do Estado, marcando o reconhecimento do status constitucional material e formal. A $2^{\circ}$ geração tornou-se reconhecida pela concreção dos direitos de igualdade ou liberdades reais ao visar a redução as desigualdades por meio de políticas públicas positivas. Os direitos da $3^{\text {a }}$ geração assemelham-se aos direitos de fraternidade ou de solidariedade que, por sua vez, relacionam-se ao estabelecimento do homem como sujeito vinculado à um planeta com recursos coletivos e finitos, que devem ser preservados e respeitados pela espécie humana (SARLET, 2012, p. 37).

No entanto, a proposta é amplamente criticada sob o argumento principal de que as “gerações” se correlacionam à uma ordem substituível (RAMOS, 2017, p. 70), enquanto que, em verdade, os direitos de liberdade, igualdade e fraternidade não foram tutelados de modo alternado 
entre si, sendo mais adequado ao que se postula a noção de "dimensões" trazida por Sarlet (2001, p. 47) e Bonavides (1998, p. 524-525).

Sobre esta "nova categoria de direitos", Mazzilli (2012, p. 50) alude que está situada em uma posição intermediária entre o âmbito público e privado, já que excede a esfera pessoal de cada indivíduo ao ser compartilhada por grupos, classes ou categorias de pessoas, mas não constitui interesse puramente público, pois, é possível extrair pretensões preponderantemente privadas.

Outras importantes características são apresentadas por Grinover (2008, p. 229), para quem estes direitos se sobressaem pela indeterminação da titularidade e indivisibilidade do objeto. A autora ainda destaca que tais particularidades são próprias de uma sociedade de massa, na qual os conflitos estão carregados de relevância política capaz de transformar conceitos já estratificados.

Neste esteio, os direitos transindividuais subsomem-se àqueles coletivos, que extrapolam o âmbito jurídico meramente individual ao atingir a esfera jurídica de grupos e coletividades, apontando titulares determinados, determináveis ou não, lastreados por pretensões divisíveis ou não (ZAVASCKI, 1995, p. 32-49).

Embora o conceito dos direitos transindividuais acima estabelecido não seja dotado de grandes controvérsias doutrinárias, o mesmo não se pode dizer da estipulação da origem histórica dos instrumentos processuais responsáveis por sua tutela, cujo estudo caminha por duas vertentes distintas.

Há quem defenda que os instrumentos processuais originaram-se na tradição romana, considerando a utilização, pelos cidadãos da época, das denominadas actio popularis, que eram tidas como um recurso processual destinado não apenas à resguardar os direitos individuais, mas também aqueles de titularidade da coletividade, partindo do sentimento de que a res publica pertencia a todos os cidadãos (GIAGNORIO, 2012).

Outros exemplos do direitos romano são trazidos por José Afonso da Silva (1968), que menciona: sepulcro violato, usada no caso de violação de sepulcro, coisa santa ou religiosa; effusis et deiects, utilizada contra quem atirasse objetos sobre a via pública; aedilitio et redhibitione et quanti minoris, visava evitar que animais perigosos fossem levados à via pública; interdictum de homine lebero exhibendo, poderia ser interposto por qualquer pessoa na defesa da liberdade, dentre outras (SILVA, 1968, p. 16-20, grifo nosso).

No entanto, por não existir uma correlação consolidada entre os procedimentos acima mencionados e aqueles que conhecemos hoje, o direito romano é classificado por Almeida (2003, p. 38) como sendo apenas a "origem remota" das ações plúrimas enquanto que a Inglaterra é apontada como o berço dos litígios coletivos pelo entendimento de Mendes (2002, p. 45).

Ressalta-se que a tutela dos direitos coletivos nos países de civil law teve considerável ascensão na década de 70 diante da elevação da tomada de consciência de que os métodos processuais tradicionais não se mostravam suficientes à tutela das espécies de interesses que 
extrapolavam a esfera individual, partindo daí a busca por técnicas capazes de cumprir bem a tarefa (THIBAU; OLIVEIRA, 2016).

Acerca deste mesmo interregno histórico, Joaquin Silguero Stagnan (1995) alude que o aprimoramento da tutela dos direitos transindividuais emerge como uma consequência da evolução e da mudança social de perspectiva das sociedades advinda das limitações de intervenção estatal, agravadas pela aparição de novos grupos informados e formadores de opinião (STAGNAN, 1995, p. 29).

Assim, temos que a afirmação dos direitos e interesses transindividuais desenvolveuse no perpassar da história na mesma medida em que as sociedades, pautando-se na elevação e concreção das necessidades fundamentais dos cidadãos e fim de impedir violações e promover o bem-estar social, o que exigiu instrumentos processuais específicos para a tutela desta "nova" categoria de direitos sendo, no entanto, encontradas origens remotas de institutos correlatos aos existentes atualmente.

\section{TUTELA DOS DIREITOS E INTERESSES TRANSINDIVIDUAIS NO BRASIL}

A Ação Popular trouxe à lume em âmbito nacional a possibilidade de tutelar as pretensões transindividuais e, como primeiro instrumento processual com esta destinação, inaugurou a proteção legal desta espécie de postulado ao conferir a qualquer cidadão a legitimidade para pleitear a anulação ou a nulidade de atos lesivos ao patrimônio público (LEONEL, 2011, p. 38).

A partir de então, o legislador infraconstitucional tratou de promulgar normativas propulsoras de direitos coletivos, tais como a LACP (Lei da Ação Civil Pública, de $n^{\circ} 7.347$, editada em 24 de julho de 1985), CDC (Código de Defesa do Consumidor, de $\mathrm{n}^{\circ}$ 8.078, editada em 11 de julho de 1990), LIA (Lei de Improbidade Administrativa, de $n^{\circ} 8.429$, editada em 2 de Junho de 1992), dentre outras, que se tornaram componentes do que se nomeia de microssistema de direitos coletivos ${ }^{3}$.

Os microssistemas jurídico-normativos são híbridos por natureza, pois reúnem e interacionam normativas de vários ramos do direito, reveladas tanto sob a forma de regra quanto sob a configuração de princípio. Com isso, têm por objetivo permitir a comunicação entre normativas, que se retro alimentam umas pelas outras, "em outras palavras, a microssistematização continuará se expandindo à medida que o dinamismo e complexidade das relações sociais assim exigirem." (RANGEL, 2018, p. 478).

A ampliação dos instrumentos de defesa das pretensões desta natureza foi corroborada pelo "reconhecimento da legitimação para a promoção de sua tutela por intermédio dos chamados corpos intermediários, representados por associações de classe, sindicatos, Ministério Público,

3 Nesse sentido: “A lei de improbidade administrativa, juntamente com a lei da ação civil pública, da ação popular, do mandado de segurança coletivo, do Código de Defesa do Consumidor e do Estatuto da Criança e do Adolescente e do Idoso, compõe um microssistema de tutela dos interesses transindividuais e sob esse enfoque interdisciplinar, interpenetram-se e subsidiam-se [...]”. (BRASIL, 2004). 
dentre outros.” (OLIVEIRA, 2011, p.41), e sua disposição na forma de conglomerado demonstra que os diplomas são intercambiantes entre si e que se assumem incompletos para aumentar a flexibilidade e durabilidade em uma realidade pluralista, complexa e dinâmica (MAZZEI, 2006).

Ademais, os mecanismos processuais específicos para o tratamento destas lides, tais como a abrangência dos pronunciamentos judiciais proferidos sob seu âmbito, a legitimidade dos postulantes e a possibilidade de fazer-se representar por entidades destinadas a defesa da coletividade, "trouxeram maior acesso ao Poder Judiciário a milhares de cidadãos que antes não chegavam ao Judiciário para buscar e proteger seus direitos.” (THAMAY, 2011, p. 263).

As especificidades do processo coletivo e a dificuldade na atribuição de efetividade (sem violações individuais) aos pronunciamentos nele exarados o diferem sobremaneira do rito comum, de modo que "não seria possível prestar tutela jurisdicional adequada aos direitos coletivos (lato sensu), se a sentença tivesse autoridade somente entre as partes em que era dada, porque, caso assim o fosse, todos os titulares do direito teriam de estar no polo ativo da ação." (BORGES; FERREIRA, 2018).

Denota-se, neste contexto, a existência de uma seara processual específica, destinada à tutelar os direitos coletivos, diante das especificidades deste tipo de pretensão, como a legitimidade, coisa julgada e liquidação de sentença. Assim, a aplicabilidade das normativas processuais clássicas, concebidas por uma filosofia liberal-individualista arraigada, são, por si só, incapazes de tutelar devidamente as pretensões transindividuais (ALMEIDA, 2003, p. 16-17).

Em que pese o reconhecimento da importância do sistema de proteção aos direitos transindividuais, é imperioso atribuir destaque individual à norma editada em 1985, que disciplinou a Ação Civil Pública e que representou verdadeiro marco nacional na evolução da proteção de direitos e interesses de grupos ao acolher, no ordenamento nacional, o procedimento que nos remete à class action americana, da qual derivaram também a action d'intérêt publique francesa, a representative action inglesa e o Odhasionprozess alemão (MARTINS FILHO, 2001).

Sobre o instrumento, Gidi (2007, p. 34) alude:

A class action é uma forma extremamente efetiva de realização das políticas públicas, uma vez que permite ao Estado conhecer e resolver a totalidade da controvérsia coletiva em um único processo. Essa visão global e unitária da controvérsia permite ao Judiciário levar em consideração todas as consequências da sua decisão, na medida em que toma conhecimento de todos os diversos interesses existentes dentro do grupo e não somente dos interesses egoísticos das partes em uma ação individual.

No contexto da presente discussão, as singularidades deste procedimento, bem ainda a latência do intento protecionista aos direitos e interesses dos representados, mostramse como vieses singulares da Ação Civil Pública que, segundo Zavascki caracterizam-se como procedimentos especiais, cuja cognição é completa, múltipla e integral, aparelhando-se como mecanismos capazes de obter, isolada ou cumulativamente, provimentos jurisdicionais da mais 
variada natureza (ZAVASCKI, 2009, p. 13).

Determinadas lesões de direitos assumem tal grau de profundidade ou de extensão que acabam comprometendo outros interesses sociais. A controvérsia decorrente da cobrança das diferenças dos expurgos inflacionários transcende a esfera individual homogênea de cada poupador, passando a representar uma soma de interesses indissociáveis, de modo a se tornar um interesse coletivo e público (ZAVASCKI, 2011, p. 47-48).

\section{O CASO DOS PLANOS ECONÔMICOS}

A instituição do microssistema de direitos coletivos ascendeu o ordenamento jurídico nacional ao patamar de grande exemplo em termos de defesa dos direitos transindividuais, cujo marco temporal nos remete ao ano de 1985, pela Lei da Ação Civil Pública.

No entanto, o mesmo avanço garantista não era verificado no âmbito político-econômico, já que, neste mesmo interregno, o país passava por imensa oscilação inflacionária. O sentimento nacional que pairava entre os cidadãos era o da falha do poder público no gerenciamento da economia e, portanto, declínio financeiro, já que "a preocupação central da política econômica residiu na inflação, seguidamente ameaçando escapar ao controle.” (MACARINI, 2009, p. 13).

$\mathrm{Na}$ tentativa de estabilizar os altos índices de modificação monetária, foram implantados planos econômicos sucessivos intitulados de Cruzado (1986), Bresser (1987) e Verão (1989) que, entretanto, resultaram em total insucesso, impondo ao governo que sobreveio a responsabilidade da tomada efetiva de mudanças capazes de frear os entraves daquele tempo, cuja ingerência causava danos tanto no campo econômico quanto no político, e ameaçava a governabilidade (ABREU; CÂMARA, 2015).

Assim, adviriam os planos Collor (1990) e Collor II (1991), igualmente fracassados na função de estabilizadores da inflação, e que foram determinantes (dentre outros fatores) para a extirpe do governante que lhes dera nome.

As mudanças no cenário econômico nacional, causadas pelo advento dos planos, causaram grandes oscilações inflacionárias, que culminaram em alterações na forma de correção das cadernetas de poupança e, consequentemente, perdas escalonadas no valor da moeda (BRITO; AGUIAR, 2018).

Resultado deste conjunto de acontecimentos foi que a população brasileira não apenas suportou lesões sucessivas em termos salariais e financeiros, como ainda os poupadores ${ }^{4}$ da época foram diretamente atingidos pela inaplicação dos reais índices da inflação pelas instituições bancárias, responsáveis pela guarda de suas quantias.

Isto por que, as altas e baixas sucessivas de alteração do valor da moeda, que por vezes não perduravam uma noite, afetaram diretamente os detentores de poupanças, pois estes tiveram suas contas desatualizadas, já que os reais índices de oscilação monetária não foram aplicados pelas instituições bancárias, culminando na existência de saldo devedor em favor do correntista.

\footnotetext{
4 Correntistas de instituições bancárias e mantenedores de contas poupança com remuneração.
} 
Nessa vereda, os expurgos inflacionários - que são a diferença entre o índice de atualização monetária utilizado para a correção dos depósitos de poupança e o índice inflacionário efetivamente vigente no início do trintídio remuneratório da poupança - , tornaram-se uns dos maiores, senão o maior, litígio nacional alçados pelos consumidores que recorreram ao Judiciário para reaver as diferenças.

Estima-se que os efeitos decorrentes desta controvérsia culminaram na acumulação do acervo aproximado de 941,4 mil processos em todas as instâncias e territórios da justiça e 656.541 apenas no STF, que correspondem tanto às postulações individuais, quanto demandas coletivas (CNJ, 2017).

A assustadora marca não se deve apenas pelo alto número de cidadãos afetados, mas também decorre logicamente da clarividente insegurança jurídica, resultado da ausência de resolução efetiva da controvérsia pelos Tribunais Superiores. Afinal, quanto maior a demora na resolução da controvérsia, mais demandas incertas são ajuizadas, muitas delas apenas para se evitar o perecimento de um direito que o jurisdicionado nem sabe se tem.

\section{O ACORDO ENTABULADO}

Diante deste calamitoso contexto de elevada judicialização e perpetuação do litígio, no intento de pôr fim a controvérsia, a Advocacia Geral da União encabeçou trabalho de mediação entre os demandantes das Ações Civis Públicas e as instituições bancárias, tendo alcançado êxito na composição ao cabo do ano de $2017^{5}$.

O documento ${ }^{6}$, que foi assinado pelos aderentes em 11 de dezembro de 2017, está colacionado nos autos do Recurso Extraordinário $n^{\circ}$ 591.797/SP e Recurso Extraordinário $n^{\circ}$ 632.212/SP e, inclusive, foi homologado pelo Supremo Tribunal Federal em decisões datadas de 18.12.17 e 05.02.2018, de autoria dos Ministros Dias Toffoli e Gilmar Mendes, respectivamente (SÃO PAULO, 2019).

Para além da rapidez de chancela da avença, que em menos de 90 (noventa) dias pôs fim a controvérsia que se discutia por 20 anos, mostra-se ainda mais evidente a sucessão de violações constantes no documento e que foram suplantadas, provavelmente, em prol de um bem maior, qual seja, extirpar o acervo das demandas dependentes desta lide.

Extrai-se da leitura da peça negocial afirmações que ratificam que a controvérsia influencia "negativamente a taxa de congestionamento em diversas unidades julgadoras do País"; que "a ausência de um solução definitiva e global para o tema coloca em risco, de um lado, a efetividade

5 São partes na transação o Instituto Brasileiro de Defesa do Consumidor - IDEC, Frente Brasileira pelos Poupadores FEBRAPO, Associação Brasileira do Consumidor - ABRACON, Associação Catarinense de Defesa do Consumidor - ACADECO, Associação para a Defesa dos Direitos Civis e do Consumidor - ADEC, Associação das Donas de Casa dos Consumidores e da Cidadania de Santa Catarina, ADOCON, Associação Paranense de Defesa do Consumidor - APADECO, Associação de Defesa dos Usuários do Sistema Financeiro de Americana e Região AUSFAR, Instituto Brasileiro de Defesa do Cidadão - IBDCI, Instituto Pro Justiça Tributária - PROJUST, Instituto Virtus de Cooperação, Desenvolvimento e Cidadania - VIRTUS de um lado, e de outro a Federação Brasileira de Bancos - FEBRABAN e a Confederação Nacional do Sistema Financeiro - CONSIF, teve ainda como interveniente o Banco do Brasil.

6 A íntegra da peça processual homologada pode ser acessada no link: http://www.stf.jus.br/arquivo/cms/ noticiaNoticiaStf/anexo/RE591797minuta.pdf. 
das providencias jurisdicionais e, de outro lado, afeta significativamente a segurança jurídica dos bancos" e que a avença visa "colocar fim ao máximo possível de litígios" (Cláusula Segunda itens 2.1.5., 2.1.6. e 3.3.).

Não há dúvidas da veracidade e propriedade destas afirmações. Porém, não se pode admitir que a mediação de conflitos coletivos, ainda mais de âmbito nacional, vise exclusivamente desafogar o Poder Judiciário e aumentar as taxas de produtividade dos julgadores.

Esta conclusão não advém apenas considerando as expressões empregadas na redação, como ainda o fato de que os próprios poupadores, que são os maiores atingidos e, consequentemente, os maiores interessados na resolução do problema, sequer foram mencionados como fundamento determinante da composição, culminando em violação do devido processo legal ao passo que a garantia de acesso à justiça deve ocorrer em toda a sua inteireza, possibilitando não só o acesso puro e simples - o ingresso em juízo - como, também, a garantia e o respeito ao verdadeiro due process of law, em seus aspectos processual e substancial (GERAIGE NETO, 2003, p. 36).

Ademais, a problemática inerente à afetação da segurança jurídica, tal qual ponderado pelos acordantes, deveria condizer muito mais com a falta de perspectiva do hipossuficiente em reaver o dano que há muito foi suportado, do que da entidade bancária, que explora a atividade empresarial de sabido poder econômico e que, ao que tudo indica, utilizou-se desde então dos valores não pagos ao depositante na época dos expurgos.

Não obstante o vício de motivação que permeia a realização do acordo, os efeitos jurídicos das disposições em si, mormente as renúncias realizadas pelos legitimados da ACP aos direitos transindividuais dos consumidores, torna a avença ainda mais ilegal e passível de nulidade.

\section{A NEGOCIAÇÃO DE DIREITOS TRANSINDIVIDUAIS EM AÇÃO CIVIL PÚBLICA}

A ascensão dos meios alternativos (ou complementares) de resolução de conflitos, aliado a atual imposição legal de "cooperação processual" das partes (art. 6º Código de Processo Civil), tornaram-se verdadeiros norteadores na atuação do Poder Judiciário, o que, decerto, foram determinantes à homologação do "Instrumento de Acordo Coletivo" entabulado no caso dos dos planos econômicos.

Em que pese o latente incentivo do legislador processual para que as demandas, inclusive as coletivas, atingissem a pacificação social por outros meios que não a submissão ao Judiciário, a verdade é que, havendo disposição de direitos transinviduais passíveis de lesar seus detentores originários, estes devem ser protegidos em detrimento de qualquer modalidade de negociação.

Considerando tratar-se de litígio coletivo, que compõe a teoria dos direitos fundamentais, mostra-se necessária a interpretação ampliativa das garantias processuais como característica inerente aos direitos constitucionais do pós positivismo (ALMEIDA; MELLO NETO, 2011, p. $81)$.

No entanto, não se verifica a concreção desta garantia quando analisamos o Acordo Coletivo entabulado no caso dos planos econômicos.

Diz-se isto considerando a completa ausência de veiculação de consultas aos 
jurisdicionados, no sentido de se verificar a aceitação, interesse e viabilidade na composição do litígio, até mesmo porque "só assim será viável a colheita de material para constatar se aquela proposta atende às exigências legais e, de forma adequada, aos interesses daqueles que não agem diretamente em juízo." (BUENO, 1996).

A resolução do maior litígio nacional, que atingiu mais de um milhão de poupadores, que são consumidores, mas que, sobretudo, são cidadãos, detentores de pretensões materiais em um Estado Democrático de Direitos, fora realizada sem quaisquer participações sociais.

Destaca-se o fato de que não foram realizadas audiências públicas, estudos econômicos acerca do impacto do acordo, quiçá foi informado ao público que tratativas estavam sendo realizadas para dirimir a controvérsia. Com efeito, os descontos, percentuais de juros, períodos e índices de correção monetária são apenas algumas informações que, apesar de negociadas pelos acordantes, não foram divulgadas antes ou depois da efetivação da avença, como ainda sequer estão corroborados por documentos técnicos ou dados estatísticos disponibilizados publicamente aos interessados.

As discussões no âmbito das demandas coletivas são muito mais abrangentes, haja vista que levam em consideração o contexto geral do problema - macrojustiça —, no entanto, quaisquer negociações devem, necessariamente, considerar o interesse coletivo no que concerne à disposição dos direitos de seus verdadeiros titulares (BARBERATO; GERAIGE NETO, 2018).

Decorre desta obscuridade a afronta à indispensável publicidade como princípio regente das ações coletivas, a se denotar a inconsistência na comprovação da ponderação nos limites de disposição do crédito dos consumidores, e da observância da garantia mínima, o que torna impossível ao jurisdicionado verificar se a proposta é ou não plausível.

Neste contexto, verifica-se que foi imposto um só resultado aos poupadores que já haviam ajuizado suas demandas individuais, ou aderido às coletivas por meio do cumprimento de sentença, eles apenas poderiam anuir sem questionar e sem poder conhecer o embasamento das condições avençadas, ou então continuariam aguardando (sem qualquer perspectiva) o provimento jurisdicional correspondente ao seu pedido.

A consequência da soma destes fatores foi a baixa aderência do público ao Acordo. Dados apurados pelos Conselho Nacional de Justiça apontam que até março de 2020 cerca de 118 mil poupadores aderiram aos termos, o que representa $12,5 \%$ de todos os processos existentes sobre o assunto em trâmite no Poder Judiciário (CNJ, 2020).

A situação desencadeou dois resultados. O primeiro foi a suspensão de todas as demandas individuais que tratam do tema pelo prazo de 24 meses, o que foi determinado pelo Supremo Tribunal Federal sob a justificativa de que a tramitação das demandas individuais estaria prejudicando a adesão ou, ao menos, o livre convencimento dos jurisdicionados ao acordo em questão.

O argumento, no entanto, não encontra respaldo. A tramitação de uma demanda submetida ao Poder Judiciário é direito fundamental da parte e dever do próprio sistema de justiça que, inafastável, deve promover o impulsionamento até a devida entrega da prestação jurisdicional. Portanto, a paralisação das demandas não tem o objetivo de auxiliar o jurisdicionado a tomar 
decisões, mas sim, pressioná-lo a aderir aos termos do acordo.

Ribeiro, Vince e Netto (2019) que a função do Poder Judiciário é a de assegurar a aplicação do direito de forma igualitária na sociedade, a fim de promover a pacificação social por meio da garantia do livre exercício dos direitos, sejam eles coletivos ou individuais.

Em que pese a persuasão, a medida não impulsionou a adesão. De acordo com o Supremo Tribunal Federal, "não se tem registro de que a suspensão nacional de liquidações, cumprimentos de sentença e execuções em trâmite no Judiciário relativamente a expurgos inflacionários decorrentes do Plano Econômico Collor II tenha efetivamente estimulado a adesão de poupadores a formularem acordos." (BRASIL, 2019).

Não obstante, cerca de $80 \%$ dos consumidores que aderiram aos termos ao Acordo Coletivo ainda não receberam os valores aceitos ${ }^{7}$.

Neste diapasão, evidencia-se o descrédito atribuído à esta avença já que os que com ela anuem não o fazem de modo espontâneo, mas sim porque estão vencidos pelo cansaço do aguardo, pela incerteza de recebimento dos valores pelas vias judiciais ordinárias, pelo desgosto geral do desconhecimento da situação e, em muitos casos, pela própria influência do Judiciário, como descreve Zanferdini (2012, p. 238):

Mediação e conciliação devem ser métodos colocados efetivamente à disposição das partes, desde o momento inicial do aparecimento do litígio, como soluções qualitativas e adequadas para cada espécie de conflito e não como propostas quantitativas a serem efetivadas em "mutirões" ou "semanas de conciliação", normalmente quando o processo já tramita há anos, consumiu recursos de toda ordem do Judiciário, bem como minou a resistência da parte mais fraca.

Não obstante, a segunda medida adotada foi a prorrogação do prazo de adesão, a extensão dos termos e a mudança das fórmulas de cálculo do montante devido. Em um aditivo homologado pelo Supremo Tribunal Federal em meados de 2020, novos moldes foram apresentados, dentre eles, a estipulação de mais prazo e o incentivo à mutirões junto ao Judiciário para fomentar a adesão (BRASIL, 2020).

As novas condições impostas denotam o intento de extirpar a controvérsia e reduzir o acervo dos julgadores, e não entregar ao jurisdicionado (que aguarda há décadas) a escorreita prestação jurisdicional, ou o ressarcimento correspondente ao dano suportado.

Cediço que o cidadão que aguardou por todo este tempo a resolução da controvérsia não busca no Poder Judiciário a aplicação da regra do "8 ou 80", no sentido de que ou aceita o acordo ou quem sabe um dia receba algo, mas com certeza, o desgaste e a incerteza mostram-se preponderantes à aderência de tão injusta.

Além disso, a maior lesão não está na situação daqueles que já demandaram suas pretensões em juízo ou aderiram às ACPs até a data do acordo, para estes, ao menos resta aderir ou

7 Informações disponíveis em: https:/extra.globo.com/noticias/economia/cerca-de-80-dos-poupadores-associadosao-idec-que-aderiram-ao-acordo-dos-planos-economicos-nao-receberam-indenizacao-23840281.html. http://cbn. globoradio.globo.com/media/audio/268885/maioria-dos-atingidos-por-planos-economicos-fracas.htm. https:// exame.abril.com.br/seu-dinheiro/79-dos-poupadores-nao-receberam-indenizacao-dos-planos-economicos/. 
não aos termos do acordo. O caso mais gravoso é o dos poupadores que aguardavam o resultado das Ações Civis Públicas para delas se aproveitarem.

É o caso dos correntistas do Banco Itaú, cujas pretensões estavam sendo discutidas no bojo do processo de $\mathrm{n}^{\circ}$ 0705843-43.1993.8.26.0100. A demanda, que tramita há duas décadas, foi julgada procedente em 1993, com sentença confirmada pelo Tribunal de Justiça do Estado de São Paulo em 1996. Não houve trânsito em julgado pela pendência de Recurso Extraordinário ao Supremo Tribunal Federal.

Considerando que a demanda ainda está em trâmite, caberia ao poupador, nos termos da lei, duas possibilidades. A primeira delas: a formulação de cumprimento provisório de sentença, sendo certo de que se trata de faculdade do credor, já que o prazo prescricional para a execução de sua pretensão sequer teve início. Lado outro, plenamente cabível ao jurisdicionado que aguardasse a definição da controvérsia na ACP, para que, somente então, postulasse o percebimento do quinhão individual por meio do cumprimento definitivo da sentença coletiva.

Ocorre que, de acordo com o quanto avençado pelas partes no Acordo Coletivo homologado pelo Supremo Tribunal Federal, “deverão ser encerrados com apresentação de petição de desistência, os recursos e incidentes processuais, além das ações autônomas que tenham como litigantes as partes ora acordantes." (BRASIL, 2018).

A cláusula subsequente evidencia ainda mais a problemática ao dispor que:

9.2. Para as ações civis públicas ainda não transitadas em julgado, e propostas dentro do prazo de prescrição quinquenal, as partes comprometem-se a apresentar petição conjunta, em que será requerida a extinção da ação coletiva por transação, consequente formação de título executivo judicial em benefício unicamente das pessoas que iniciaram cumprimento provisório de sentença coletiva até 31/12/2016 (BRASIL, 2018).

De acordo com os termos transacionados, os poupadores que optaram pela faculdade processual de realizar o cumprimento provisório da sentença coletiva até 31/12/2016, seria garantida a possibilidade de aderência ao acordo. No entanto, aos que aguardavam o trânsito em julgado de uma sentença coletiva que, até então, foi confirmada por duas instâncias do Poder Judiciário, o Acordo Coletivo prevê a renúncia de todas as pretensões, acrescendo à isto o impedimento futuro e irrestrito da discussão da controvérsia.

A desistência do Recurso Extraordinário cumulada ao pedido de extinção da demanda por transação, resultou a todos que aguardavam o trânsito em julgado para realizar o cumprimento da sentença coletiva o declínio completo das pretensões sem qualquer aviso prévio.

Portanto, temos duas situações: a) àqueles que já iniciaram o cumprimento provisório, terão suas pretensões extintas, já que estarão executando comando ineficaz, suplantado pela desistência do recurso e pela extinção da demanda, cabendo-lhes, quando muito, aderir ao Acordo e, b) àqueles que aguardavam o trânsito em julgado para o cumprimento do comando decisório, foram completamente lesados pela desistência do recurso e consequente extinção da demanda. 
Nesse viés, a renúncia realizada fere de modo frontal não apenas a boa-fé processual, exigida aos litigantes, mas ainda viola ditames constitucionais e coletivos básicos ao a) obstar o acesso à justiça pelos detentores da pretensão material, b) impor limite temporal pretérito para o exercício do direito de petição que sequer era obrigatório, c) impossibilitar a ampla participação na negociação, e d) desistir de pretensões coletivas já reconhecidas em juízo.

O Código Civil, que disciplina o instituto da transação processual, garante no art. 841 que a disposição de direitos pelo seu titular apenas pode ocorrer quando estes forem patrimoniais e de caráter privado.

No caso dos planos econômicos, o fator preponderante é a existência de pretensões coletivas, cujos detentores podem ser apontados, e que se coadunam por pedidos de natureza financeira, quais sejam, o percebimento do montante produto da diferença entre o valor pago pelas entidades bancárias à época dos expurgos, e aquele efetivamente devido. Identificam-se, assim, pretensões transindividuais, de caráter individual homogêneo.

Portanto, não estamos diante de transação efetivada pelo titular da pretensão material, mas sim, por substituto processual, na qualidade de representante legitimado pelo art. $5^{\circ}$ da Lei 7.347/85, nos autos de Ação Civil Pública.

Neste espeque, aplicável a regra da legitimação extraordinária, no sentido de que, em se tratando de atuação em nome próprio, mas na defesa de direito alheio, os atos praticados apenas se aplicam ao representado se lhe forem favoráveis, até mesmo por que os colegitimados não possuem autonomia material de atuação ao ponto de serem aptos a dispor de direitos que sequer são titulares, ainda que estes sejam de caráter disponível (MAZZILLI, 2014, p. 462).

Para Bosquê (2019), a transação processual, ou o negócio jurídico processual, somente é possível em casos de direitos que admitem autocomposição, cabendo ao Judiciário realizar o controle de validade e a aplicabilidade no caso concreto, nos termos do parágrafo único do art. 190 do CPC, que dispõe: “[...] de ofício ou a requerimento, o juiz controlará a validade das convenções previstas neste artigo, recusando-lhes aplicação somente nos casos de nulidade ou de inserção abusiva em contrato de adesão ou em que alguma parte se encontre em manifesta situação de vulnerabilidade." (BRASIL, 2015).

Por analogia, Didier Junior e Zanetti Junior (2017b) afirmam que as regras da transação presentes no regramento processual comum aplicam-se aos direitos coletivos, pois, ao se reconhecer constitucionalmente a tutela dos direitos coletivos, não se pode impedir sua efetivação, mormente pela via consensual (como é o caso da aderência ao acordo), e também porque o caráter indisponível da pretensão não será afetado, na medida em que visa, com a transação, a sua maior efetivação.

No entanto, e conforme outrora apontado, a negociação em análise não primou pela amplitude de efetivação de direitos, mormente por limitar temporal e materialmente os poupadores que poderiam aderir à ela e, ainda, ressaltar a renúncia a direitos reconhecidos em outras demandas.

A problemática inerente à renúncia de direitos e interesses coletivos é também evidenciada por Arenhart ao afirmar que se trata de conduta corriqueiramente aceita no ordenamento brasileiro, 
embora a considere verdadeira violação ao titular do direito, e aduz:

[...] em um meio no qual o interesse pertence à coletividade ou a um grupo que é tão-somente "representado" pelo autor da ação coletiva, fica evidente o disparate dessa conclusão. Como é possível que alguém que não é o titular do direito possa dispor do direito alheio no processo, sem qualquer consequência? Não obstante a obviedade dessa indagação, parece que ela é irrelevante na lógica do processo coletivo brasileiro, que trabalha tranquilamente com essa possibilidade (ARENHART, 2016, p. 5).

Os limites da legitimação coletiva devem condizer diretamente com a margem da garantia de proteção daqueles que não constam nos polos da demanda, de modo que, em sendo desfavoráveis as disposições avençadas pelo representante processual, não há que se falar em vinculação do jurisdicionado, mas sim, em reconhecimento da desvirtuação da legitimidade, culminando em sua necessária substituição por outro colegitimado que melhor defenda os direitos em voga.

O controle judicial da validade e aplicabilidade dos termos negociados deve ser analisado subjetivamente, de modo que, em sendo desfavorável ao poupador, torna-se inaplicável ao caso concreto. A manifesta situação de vulnerabilidade do jurisdicionado que teve sua pretensão individual renunciada por um legitimado coletivo, nos autos da ACP, permite que as disposições avençadas sejam afastadas, desde que devidamente invocada nos autos da demanda individual.

O interesse público pela guarda e concreção do direito coletivo deve ser tutelado pelo afastamento das diretrizes desfavoráveis ao titular da pretensão material, consoante aludem Didier Junior e Zanetti Junior (2017b, p. 130):

Primeiro, há necessidade de tutela do objeto litigioso do processo, presente o interesse público, por se tratar de direitos de natureza coletiva; segundo, há necessidade da participação dos grupos que serão afetados pela decisão e da participação dos colegitimados, pelo menos potencialmente, no âmbito do acordo a ser firmado; terceiro, há a intervenção obrigatória do Ministério Público em todas os processos que tratam dos direitos coletivos em sentido lato. A atividade do juiz nestes casos não será, contudo, meramente confirmatória do acordo, em juízo simplista de delibação, no qual se verificam apenas os aspectos formais de representação das partes. O juiz, nestas oportunidades, deverá proceder a um verdadeiro exame de mérito do compromisso, possibilitando até mesmo sua discordância, caso em que não será homologado o acordo.

Outrossim, inconcebível que o próprio legitimado, à quem é atribuída e exigida a guarda e proteção da pretensão coletiva, seja idealizador e anuente da desistência irrestrita do direito de incontáveis poupadores. Trata-se de gravíssimo desvio de conduta por parte dos demandantes, em especial o IDEC, passível de condenação por litigância de má-fé, ato atentatória à dignidade da justiça, sem prejuízo da imediata substituição por outro interessado devido à perda superveniente da legitimidade pela incongruência de interesse pessoal com o interesse público.

Em que pese se tratar de providências indispensáveis, mostram-se ineficazes considerando 
que a avença já foi homologada pelo Supremo Tribunal Federal, tendo tal decisão transitado em julgado, razão esta pela qual oportuno traçar comentários acerca da possibilidade de impugnação à referida disposição, iniciando pela análise dos efeitos, eficácia e efetividade.

Os efeitos, na concepção de Carnelutti (1936, p. 60), são entendidos como as mudanças de uma situação precedente, enquanto que "pode-se falar em eficácia como simples aptidão de produzir efeitos (em potência), como em um conjunto de efeitos verdadeiramente produzidos (em ato).” (MOREIRA, 1989, p. 175-176).

De outro vértice, Ovídio Baptista os distingue da eficácia, utilizando-se de uma analogia. Como se a sentença fosse um medicamento, nos dizeres do autor, a eficácia equivaleria à "virtude curativa" deste, enquanto que os efeitos são os resultados por ele proporcionado, ou seja, "não se pode confundir a virtude curativa com o efeito produzido pelo medicamento sobre o organismo do enfermo. A eficácia ainda não é o efeito do medicamento" (SILVA, 2003, p. 176), o que também difere do que acolhemos por efetividade, que, nos ditames de Eduardo José da Fonseca Costa (2005, p. 282), significa o grau de materialização dos preceitos normativos no mundo dos fatos.

Assim, a decisão que homologou a avença tem o âmbito de sua eficácia garantia, já que prolatada por órgão competente dotado de jurisdição, mas não produz efeitos na ordem jurídica, considerando a ausência de legalidade e constitucionalidade à ele atribuída, sendo nula de pleno direito nos termos do art. 51 do Código de Defesa do Consumidor (BRASIL, 1990).

Ademais, por meio de interpretação sistemática atribuída ao parágrafo único do art. 436 do Código Civil (BRASIL, 2002), que trata da estipulação em favor de terceiro, novamente tem-se que aquele em favor de quem se estipulou apenas se vincula às disposições se optar pela exigência de cumprimento das obrigações. O contrário, portanto, também é verdadeiro. Ou seja, a realização de acordo por terceiros, em favor de um determinado grupo de jurisdicionados, apenas os vinculam se estes exigirem seu cumprimento.

Sendo assim, possível suscitar em querela nulitatis a relativização dos efeitos da coisa julgada, fulcrando-se no entendimento de Didier Junior e Zanetti Junior (2017b, p. 345) para quem "a coisa julgada, caso existe homologação de acordo nestes casos, será rebus sic standibus: sobrevindo circunstancia de fato que altere a situação definida na sentença poderá ser reproposta nova ação."

Teresa Arruda Alvim Wambier e José Miguel Garcia Medina (2008, p. 388) também se perfilham à corrente ao aludirem que "a coisa julgada exerce função positiva e negativa, que se explicam a partir do princípio da segurança jurídica", e assim, para a revisão do pronunciamento eivado de vícios, tais como a inconstitucionalidade, faz-se suficiente a pretensão declaratória de nulidade:

As sentenças que são inconstitucionais porque acolhem pedidos inconstitucionais, são sentenças (estas sim!) que não transitam em julgado por que foram proferidas em processos instaurados por meio de mero exercício de direito de petição (e não de direito de ação!) já que não havia possibilidade jurídica do pedido.[...] Portanto, em nosso entender, a parte interessada deveria, sem necessidade de se submeterão prazo do art. 495 do CPC, intentar ação de natureza declaratória, 
com o único objetivo de gerar maior grau de segurança jurídica à sua situação (WAMBIER; MEDINA, 2008, p. 390).

Trilhando por outra linha, fundamentada na violação ao próprio texto do Acordo Coletivo entabulado, cujas disposições são dotadas de força vinculante com a prevalência do convencionado sobre o legislado segundo a Cláusula 11.2., o cabimento de demanda declaratória, para suscitar a ausência de validade dos termos avençados devido à notável infringência a) da segurança jurídica, considerando que os acordantes renunciaram à direitos reconhecidos por sentença, confirmada pelo TJSP, e que estavam sendo executados pelos detentores da pretensão, em total detrimento dos consumidores que não foram sequer informados sobre a possibilidade de disposição de seus direitos; b) do exaurimento da macro-lide, considerando não apenas a baixa aderência aos termos acordados, como ainda a continuidade no ajuizamento de demandas, à exemplo do que se vislumbra da análise do tramite processual nos autos de $n^{\circ}$ 0705843-43.1993.8.26.0100.

Portanto, a disposição de direitos em Ação Civil Pública, embora cabível, deve ser dotada de cautelas indelegáveis, sem que se perca como norte "a efetivação do acesso - individual e metaindividual - dos fracos e vulneráveis, como consumidores, trabalhadores, crianças, adolescentes, idosos, os excluídos em geral, não apenas ao aparelho judiciário e à democratização das suas decisões, mas, sobretudo, a uma ordem jurídica justa.” (LEITE, 2012, p. 156).

\section{CONCLUSÃO}

As primeiras demandas de grupos datam do direito romano, e as previsões legais brasileiras que sobrevieram sobre o tema, em sua grande maioria, consolidam o viés de que disciplinar a pulverização dos litígios têm se tornado não apenas uma tendência, mas ainda necessidade do legislador contemporâneo para lidar com a massificação das relações e a judicialização dos conflitos.

Em que pese a evolução das disposições protetivas, em especial a vigência da LACP, demonstramos no transcorrer deste estudo que o Judiciário caminhou na contramão na legalidade, incorrendo em violação dos direitos fundamentais do jurisdicionado ao homologar o acordo entabulado pelas Associações representantes dos consumidores e as instituições bancárias, no caso dos expurgos inflacionários.

A delonga na resolução da controvérsia, que tramita há duas décadas no Judiciário, ressalta o declínio da justiça nacional que, abarrotada, trabalha em regime de contingência de demandas para suprir a ineficácia do sistema jurisdicional e a consequente insegurança jurídica, devido à falta de perspectiva de resolução deste percalço.

No entanto, suplantar a celeridade e a diminuição de acervo, em detrimento da concreção dos direitos individuais homogêneos dos poupadores, importa em afronta à ditames constitucionais, como o acesso à justiça, contraditório, ampla defesa e a inafastabilidade da jurisdição.

O Acordo Coletivo que ora se analisou fora entabulado por aqueles que se dizem protetores dos direitos dos consumidores, enquanto que estes últimos, propriamente, sequer foram indagados 
sobre a resolução da controvérsia, não tendo sido realizada audiência pública, pesquisa via internet ou qualquer outra forma de consulta popular aos legítimos detentores da pretensão. Destaca-se a carência de embasamento em documento técnico hábil a comprovar que a disposição dos direitos coletivos, como fatores preponderantes ao notório insucesso do Acordo, e sua baixa aderência pelos consumidores.

Os termos acordados não contam com qualquer lastro de legalidade, devido a ausência de legitimidade de seus componentes. Até mesmo por que tanto o desconto no crédito para os aderentes, quanto a arbitrária desistência das demandas já julgadas, caminham na contramão da legalidade, efetividade, validade e respeito aos preceitos basilares do Estado Democrático de Direito, não havendo lastro para sua convalidação no ordenamento pátrio.

Portanto, embora se admita a disposição de direitos coletivos em Ação Civil Pública, mormente representada pela transação processual, conclui-se que o ato deve ser balizado por preceitos efetivos, moldados pela atuação ativa do Judiciário - que não apenas se limita a homologar, mas sim a realizar verdadeiro filtro de validade - , lastreado na publicidade, na participação e consulta popular, na realização der estudos técnicos. E, em sendo desfavorável ao detentor da pretensão material, cabível o afastamento das disposições negociadas no caso concreto, sem prejuízo das ferramentas processuais de arguição da nulidade e recursos, nos autos das Ações Coletivas. Tudo isto para impedir que as negociações não resultem em violações aos direitos em discussão, como ainda para garantir que sejam incapazes de produzir efeitos nocivos àqueles que sequer participaram de sua formulação, cuja vulnerabilidade se evidencia.

\section{REFERÊNCIAS}

ABREU, Cilair Rodrigues de; CÂMARA, Leonor Moreira. O orçamento público como instrumento de ação governamental: uma análise de suas redefinições no contexto da formulação de políticas públicas de infraestrutura. Revista da Administração Pública, Rio de Janeiro, p. 73-90, jan./fev. 2015.

ALMEIDA, Gregório Assagra de. Direito processual coletivo brasileiro: um novo ramo do direito processual (princípios, regras interpretativas e a problemática da sua interpretação e aplicação). São Paulo: Saraiva, 2003.

ALMEIDA, Gregório Assagra de; MELLO NETO, Luiz Philippe Vieira de. Fundamentação constitucional do direito material coletivo e do direito processual coletivo: reflexões a partir da nova summa divisio adotada na CF/88 (Título II, Capítulo I). Revista do TST, Brasília, v. 77, n. 3, p. 77-97, jul./set. 2011 .

ARENHART, Sérgio Cruz. Processos estruturais no direito brasileiro: reflexões a partir do caso da ACP do carvão. Revista de Processo Comparado, Curitiba, v. 2, 2016. Disponível em: https://edisciplinas.usp.br/pluginfile.php/4875393/mod_resource/content/0/ ARENHART\%2C\%20S\%C3\%A9rgio.\%20Processos\%20Estruturais.pdf. Acesso em: 22 mar. 2021.

BARBERATO, Celso; GERAIGE NETO, Zaiden. A ação coletiva como instrumento de tutela e 
concretização do direito à saúde. Revista Jus Populis, Salvador, v. 1, p. 129-146, 2018.

SILVA, Ovídio Baptista da. Sentença e coisa julgada: ensaios e pareceres. Rio de Janeiro: Forense, 2003.

BONAVIDES, Paulo. Curso de Direito Constitucional. 7a ed. Malheiros, São Paulo, 1998.

BORGES, Daniela Meca; FERREIRA, Olavo Vianna Alves. Limitação territorial da coisa julgada como óbice ao acesso à justiça. Revista Opinião Jurídica, Fortaleza, ano 16, n. 23, p. 160-183, jul./dez. 2018.

BOSQUÊ, Déborah Sant'Anna Lima. Revista Jurídica Luso Brasileiro, Lisboa, Ano 5, n. 4, p. 625-662, 2019.

BRASIL. Lei no 10.406, de 10 de janeiro de 2002. Institui o Código Civil. Brasília, DF: Presidência da República, 2002. Disponível em: http://www.planalto.gov.br/ccivil_03/leis/2002/ L10406compilada.htm. Acesso em: 22 mar. 2021.

BRASIL. Lei n 13.105, de 16 de março de 2015. Código de Processo Civil. Brasília, DF: Presidência da República, 2015. Disponível em: http://www.planalto.gov.br/ccivil_03/_ato20152018/2015/lei/113105.htm. Acesso em: 22 mar. 2021.

BRASIL. Lei $\mathbf{n}^{\mathbf{0}}$ 8.078, de 11 de setembro de 1990. Dispõe sobre a proteção do consumidor e dá outras providências. Brasília, DF: Presidência da República, 1990. Disponível em: http://www. planalto.gov.br/ccivil_03/leis/18078compilado.htm. Acesso em: 22 mar. 2021.

BRASIL. Supremo Tribunal Federal. Instrumento de acordo coletivo. Diário Oficial da União: Seção 1, Brasília, DF, Ed. 23, p. 1-7, 1 fev. 2018.

BRASIL. Supremo Tribunal Federal. Ministro reconsidera decisão que determinou suspensão nacional de processos envolvendo Plano Collor II. Brasília: STF, abr. 2019. Disponível em: http://www.stf.jus.br/portal/cms/verNoticiaDetalhe.asp?idConteudo=408183. Acesso em: $22 \mathrm{mar}$. 2021.

BRASIL. Supremo Tribunal Federal. Arguição de Descumprimento de Preceito Fundamental no 165 Distrito Federal. Brasília: STF, 2020. Disponível em: http://www.stf.jus.br/arquivo/cms/ noticiaNoticiaStf/anexo/ADPF165termoaditivo3.pdf. Acesso em: 22 mar. 2021.

BRASIL Tribunal de Justiça ( $1^{\text {a }}$ Turma). RESP no 510.150/MA. Administrativo e processual. Improbidade administrativa. Recorrente: Jose Camera Ferreira. Recorrido: Ministério Público do Estado do Maranhão. Relator: Min. Luiz Fux, 17 de fevereiro de 2004.Disponível em: https:// stj.jusbrasil.com.br/jurisprudencia/7381445/recurso-especial-resp-510150-ma-2003-0007895-7/ inteiro-teor-13045218. Acesso em: 22 mar. 2021.

BRITO, Cristiane dos Santos; AGUIAR, Simone Coêlho. Os Planos Econômicos Cruzado, Bresser, Verão, Collor I e II e os Recursos Extraordinários 591.797 e 626.307: impactos nas finanças do estado brasileiro em face das vindouras decisões do STF. Revista de Estudos Jurídicos UNESP. Franca, a.22, n.36, 2018.

BUENO, Cassio Scarpinella. As class actions norte-americanas e as ações coletivas brasileiras: 
pontos para uma reflexão conjunta. Revista de Processo, São Paulo, n. 82, p. 92-151, abr./jun. 1996. Disponível em: http://scarpinellabueno.com/images/textos-pdf/004.pdf. Acesso em: 22 mar. 2021.

CARNELUTTI, Fracesco. Sistema del diritto processuale civile. Padova: Cedam, 1936. v. 2.

CNJ - CONSELHO NACIONAL DE JUSTIÇA. CNJ apresenta o primeiro relatório analítico do Supremo. Brasília: CNJ, 2017. Disponível em: https://www.cnj.jus.br/cnj-apresenta-oprimeiro-relatorio-analitico-do-supremo/. Acesso em: 22 mar. 2021.

CNJ - CONSELHO NACIONAL DE JUSTIÇA. Resolve: poupança - planos econômicos. Brasília: CNJ, 2020. Disponível em: https://app.powerbi.com/view?r=eyJrIjoiYjk3YWFlMjktMGY3NC00ZmI0LThiMzQtN2I1MWVjY2VINGRjIiwidCI6ImFkOTE5MGU2LWM0NWQtNDYwMC1iYzVjLWVjYTU1NGNjZjQ5NyIsImMiOjJ9. Acesso em: 21 mar. 2021.

COSTA, Eduardo José da Fonseca. As noções jurídico processuais de eficácia, efetividade e eficiência. Revista de Processo, São Paulo, v. 121, mar. 2005.

DIDIER JUNIOR, Fredie; ZANETI JUNIOR, Hermes. Curso de direito processual civil: processo coletivo. 11. ed. Salvador: Ed. JusPodivm, 2017 a.

DIDIER JUNIOR, Fredie; ZANETI JUNIOR, Hermes. Justiça multiportas e tutela constitucional adequada: autocomposição em direitos coletivos. Revista da Procuradoria-Geral do Estado do Espírito Santo, Vitória, v. 15, n. 15, p. 111-142, 2017 b.

GERAIGE NETO, Zaiden. O princípio da inafastabilidade do controle jurisdicional. São Paulo: Revista dos Tribunais, 2003.

GIAGNORIO, Michele. Brevi note in tema di azioni popolari. Teoria Estória del Diritto Privato, Salerno, n. 5, 2012. Disponível em: http://www.teoriaestoriadeldirittoprivato.com/ media/rivista/2012/contributi/2012_Contributi_Giagnorio_AzioniPopolari.pdf. Acesso em: 22 mar. 2021.

GIDI, Antonio. A class action como instrumento de tutela coletiva dos direitos: as ações coletivas em uma perspectiva comparada. São Paulo: Editora Revista dos Tribunais, 2007.

GRINOVER, Ada Pellegrini. Os processos coletivos nos países de civil law e common law: uma análise de direito comparado. São Paulo: Revista dos Tribunais, 2008.

GUERRERO, Ana Luisa. Reflexiones ético-políticas sobre los derechos colectivos de los pueblos indígenas. Revista Nuestramérica, Concepción, v. 6; n. 11, 2018.

LEITE, Carlos Henrique Bezerra. O acesso coletivo à justiça na perspectiva dos direitos humanos. In: DIDIER JUNIOR, Fredier (coord.). Tutela jurisdicional coletiva. Salvador: Editora Juspodivm, 2012.

LEONEL, Ricardo de Barros. Manual do processo coletivo. São Paulo: Revista dos Tribunais, 2011.

MACARINI, José Pedro. A política econômica do governo Sarney: os planos cruzados (1986) e Bresser (1987). Campinas: Unicamp, 2009. Texto para Discussão. IE/Unicamp, n. 157, mar. 
Disponível em: www.eco.unicamp.br/docprod/downarq.php?id=1787\&tp=a. Acesso em: 22 mar. 2021.

MARTINS FILHO, Ives Gandra da Silva. A importância da ação civil pública no âmbito trabalhista. Revista Jurídica Virtual, Brasília, v. 3, n. 25, jun. 2001.

MAZZEI, Rodrigo Reis. A ação popular e o microssistema da tutela coletiva. In: GOMES JUNIOR, Luiz Manoel (coord.). Ação popular: aspectos controvertidos e relevantes -40 anos da Lei 4717/65. São Paulo: RCS, 2006. p. 408-410.

MAZZILLI, Hugo Nigro. A defesa dos interesses difusos em juízo: meio ambiente, consumidor, patrimônio cultural, patrimônio público e outros interesses. 25. ed. São Paulo: Saraiva, 2012.

MAZZILLI, Hugo Nigro. A defesa dos interesses difusos em juízo: meio ambiente, consumidor, patrimônio cultural, patrimônio público e outros interesses. 27. ed. São Paulo: Saraiva, 2014.

MENDES, Aluisio Gonçalves de Castro. Ações coletivas no direito comparado e nacional. São Paulo: Editora Revista dos Tribunais, 2002.

MOREIRA, José Carlos Barbosa. Conteúdo e efeitos da sentença: variações sobre o tema. In: MOREIRA, José Carlos Barbosa. Temas de direito processual: quarta série. São Paulo: Saraiva, 1989.

OLIVEIRA, Marcelo Henrique Matos. Considerações sobre os direitos transindividuais. Revista Jurídica Cognitio Juris. João Pessoa, v. 1, n. 2, p. 37-49, 2011.

RAMOS, André de Carvalho. Curso de direitos humanos. 4. ed. São Paulo: Saraiva, 2017.

RANGEL, Rafael Calmon. A interatividade entre os sistemas, subsistemas, minissistemas e microssistemas jurídico-normativos de tutela dos direitos dos consumidores. Revista de Direito do Consumidor, São Paulo, v. 117, n. 1, p. 469-488, 2018.

RIBEIRO, Daniela Menengoti Gonçalves; VINCE, Fernando Navarro; NETTO, João Paulo Gomes. Acesso à justiça: a tutela coletiva de direitos individuais homogêneos e dos direitos da personalidade. Revista Juris Poiesis. Rio de Janeiro, v. 22, n. 30, p. 264-282, 2019.

SÃO PAULO. Recurso Extraordinário 632.212. Recorrente: Banco do Brasil S/A. Recorrido: Célia Natalina de Leão Bensadon. Relator: Min. Gilmar Ferreira Mendes, 11 de abril de 2019. Disponível em: http://portal.stf.jus.br/processos/downloadPeca.asp?id=15339910273\&ext=.pdf. Acesso em: 22 mar. 2021.

SARLET, Ingo Wolfgang. Dignidade da Pessoa Humana e Direitos Fundamentais na Constituição Federal de 1988. Porto Alegre: Livraria do Advogado Editora, 2011.

SARLET, Ingo Wolfgang. A eficácia dos direitos fundamentais: uma teoria geral dos direitos fundamentais na perspectiva constitucional. 11. ed. Porto Alegre: Livraria do Advogado Editora, 2012. 
SBDP - SOCIEDADE BRASILEIRA DE DIREITO PÚBLICO. Ações coletivas no Brasil: o processamento, o julgamento e a execução das tutelas coletivas. 2017. Disponível em http:// www.sbdp.org.br/research/acoes-coletivas-no-brasil-o-processamento-o-julgamento-e-aexecucao-das-tutelas-coletivas/. Acesso em: 30 jul. 2020.

SILVA, José Afonso da. Ação popular constitucional: doutrina e processo. São Paulo: Editora Revista dos Tribunais, 1968.

STAGNAN, Joaquin Silguero. La tutela jurisdicional de los interesses colectivos a traves de la legitimacion de los grupos. Madrid: Editora Dykinson, 1995.

THAMAY, Rennan Faria Krüger. O processo civil coletivo: aspectos de um novo direito processual. Revista Opinião Jurídica, Fortaleza, v. 11, n. 15, p. 261-293, jan./dez. 2011.

THIBAU, Tereza Cristina Sorice Baracho; OLIVEIRA, Izabela Cristina de. Tutela jurisdicional coletiva: aspectos históricos e o microssistema de tutela dos direitos coletivos no direito brasileiro. Revista Paradigma, Ribeirão Preto, v. 25, n. 1, p. 102-124, jan./jun. 2016.

VASAK, Karel. For the third generation of human rights: the rights of solidarity. In: VASAK, Karel .The internacional dimensiono f human rights. Paris: Unesco, 1982. 2 v.

WAMBIER, Teresa Arruda Alvim; MEDINA, José Miguel Garcia. Relativização da coisa julgada. In: DIDIER JUNIOR, Fredie (org.). Relativização da coisa julgada. 2. ed. Salvador: Juspodivm, 2008.

ZANFERDINI, Flávia de Almeida Montingelli. Desjudicializar conflitos: uma necessária releitura do acesso à justiça. Revista NEJ - Eletrônica, Itajaí, v. 17, n. 2, p. 237-253, maio/ ago. 2012. Disponível em: https://siaiap32.univali.br/seer/index.php/nej/article/view/3970/2313. Acesso em: 22 mar. 2021.

ZAVASCKI, Teori Albino. Defesa de direitos coletivos e defesa coletiva de direitos. Revista de Processo, São Paulo, v. 78, n. 1, p. 32-49, 1995.

ZAVASCKI, Teori Albino. Processo coletivo: tutela de direitos coletivos e tutela coletiva de direitos, São Paulo: Editora Revista dos Tribunais, 2011.

ZAVASCKI, Teori Albino. Reforma do processo coletivo: indispensabilidade de disciplina diferenciada para direitos individuais homogêneos e para direitos transindividuais. Revista Justiça \& Cidadania, Rio de Janeiro, Ed. 104, 2009. Disponível em: https://core.ac.uk/download/ pdf/79062876.pdf. Acesso em: 22 mar. 2021.

Como citar: SIQUEIRA, Oniye Nashara; NETO, Zaiden Geraige. The (in)availability of transindividual rights in class actions: analysis of the case of economic plans. Scientia Iuris, Londrina, v. 25, n. 1, p. 87-108, mar. 2021. DOI: 10.5433/2178-8189.2021v25n1p87. ISSN: 21788189.

Recebido em 05/10/2020

Aprovado em 22/03/2021 